\title{
Developing Students' Intercultural Sensitivity at the Home Campus: An Innovative Approach Using the Theory of the Creative Action Methodology Pedagogy
}

\begin{abstract}
Higher education institutes, including research universities and universities of applied sciences, face the challenge of developing effective internationalisation practices to prepare students for the demands of a globalising world. Researchers reporting on studies that are focused on universities' internationalisation practices show that few practices are effective to develop students' intercultural sensitivity. Broadly speaking, intercultural sensitivity means the ability to distinguish between real differences in values and behaviours across cultures, as well as the appreciation of values and behaviours even if they differ from one's own. Interestingly, across the board researchers do not provide an explanation of what drives intercultural sensitivity development. This study reports on the impact of a new learning intervention that effectively developed local Dutch students' intercultural sensitivity in the Netherlands, and it provides an explanation of this impact. For the intervention the theory of the Creative Action Methodology pedagogy (CAM) was used as a heuristic tool. CAM is a pedagogical approach that focuses on developing critical, analytical, and creative skills by having students break away from a culture of the truth. Results in this mixed-methods study, using the Intercultural Development Inventory and interviews, reveal that students significantly developed their intercultural sensitivity as they became empowered to break away from a culture of the truth.
\end{abstract}

KEYWORDS

intercultural sensitivity, Creative Action Methodology, higher education

\section{INTRODUCTION}

The objective of this research is to propose a theory-informed explanation of intercultural sensitivity development, propose a pedagogical approach that is grounded in the theory, and to systematically investigate the impact of that learning intervention on students' intercultural sensitivity. The term 'explanation' does not refer here to a statistical explanation, e.g., correlations. Instead, the term 'explanation' refers to an understanding, "Verstehen" (Moses and Knutsen 2007,184 ), about the influence of a pedagogical approach on intercultural sensitivity development.

This study also serves to support the design of effective internationalisation at home activities for higher education institutes (HEI), including research universities and universities of applied sciences, that seek to prepare students for an ever-globalising work field and world. The location of this study is at the Avans School of International Studies (ASIS) which is an international business school. ASIS is part of the Avans University of Applied Sciences located in Breda, the Netherlands. ASIS has approximately 1,000 students, $25 \%$ of whom come from countries outside the Netherlands. 
In this study intercultural sensitivity is defined as "the ability to discriminate and experience relevant cultural differences” (Hammer, Bennett, and Wiseman 2003, 422). The ability 'to discriminate' in this case means that one can make distinctions between cultures (Bennett 1993). Broadly speaking there are two fundamental opposing ways of experiencing relevant cultural differences: Either one experiences cultural differences through an ethnocentric view or through an ethnorelative view (Bennett 2012). If one engages differences in culture through an ethnocentric view, one experiences their own cultural values and behaviours as central to reality and other cultures as a threat to their own culture (Bennett 1993; Hammer 2012). If one experiences other cultural values and behaviours as equally relevant and viable, this is referred to as an ethnorelative view (Bennett 2012). As one develops their intercultural sensitivity one also develops their potential to become interculturally competent by behaving and communicating effectively and appropriately in intercultural contexts (Hammer 2012).

There has been an increasing emphasis in higher education on the development and offering of intercultural education (de Wit 2010). Ministries of Education from around the world, such as those from Malaysia, the Netherlands, Sweden, and Australia have stressed the importance of developing students' intercultural sensitivity (Australian Government 2021; Bussemaker 2014; Ministry of Education Malaysia 2013; Swedish Government Inquiries 2018). A key driver for this emphasis lies in the globalisation of our world in general and the work field in specific (Knight 2008). The work field is globalising and this requires professionals to cooperate effectively with clients and colleagues who increasingly come from other cultures (Tillman 2012; Trilling and Fadel 2009). Thus, intercultural sensitivity development helps students to become employable (Australian Government 2021; Ministry of Education Malaysia 2013; Swedish Government Inquiries 2018).

Therefore, intercultural sensitivity is a necessity for anyone to successfully work and live in today's highly globalised world (Trilling and Fadel 2009). HEIs have developed internationalisation practices to prepare their students for a career and life in an ever-globalising world and to strengthen the competitiveness of their countries' economies (Knight 2008).

\section{Challenges to intercultural sensitivity development}

Research shows that becoming interculturally sensitive is by no means a default outcome of educational activities, whether these include trips abroad, transfer of cultural knowledge components, or having a culturally diverse student body (Bennett 2012; Hammer 2012). By tendency people engage cultural differences with an ethnocentric view (Pusch 2009). Moving away from an ethnocentric view to an ethnorelative view represents a major shift in one's worldview that requires active intercultural learning interventions (Bennett 2012; Olson and Kroeger 2001). On this note, there are three things that are striking from the plethora of studies from across the world in which the effect of intercultural learning interventions at schools are examined: First, different teaching approaches are utilised in interventions to develop learners' intercultural sensitivity. Second, the impact of these interventions varies. Third, authors fail to provide an explanation that goes beyond mere correlations and that could provide an understanding, "Verstehen" (Moses and Knutsen, 2007, 184) on the causes of the interventions' effects or lack thereof.

To illustrate, researchers did not provide an explanation beyond mere correlations for the lack of any significant changes in students' intercultural sensitivity or competence even though they had organised intercultural coursework that included activities such as: cultural values, attitudes, and intercultural issues (Altshuler, Sussman, and Kachur 2003; Gordon and Mwavita 2018) or the promotion of intercultural interaction (Prieto-Flores, Òscar, and Casademont 2016; Young, Haffejee, and Corsun 2017). 
Similarly, in studies that show (moderately) positive impacts of interventions containing learning activities of promoting interaction between local and international students (Eisenchlas and Trevaskes 2007; Jon 2013), analysing intercultural TV ads (Tirnaz and Narafshan 2018), teaching conflict resolution (Behrnd and Porzelt 2012), and investigating cultural stereotypes (López-Rocha and Vailes 2017), a more fundamental explanation is missing as to why students developed their intercultural sensitivity and/or competence.

An often-cited model of intercultural sensitivity and competence by Deardorff (2006) shows that a combination of knowledge, attitude, and skills components is necessary to develop one's intercultural sensitivity which then contributes to one's potential to demonstrate appropriate and effective behaviour in intercultural settings. Yet, this model does not provide an explanation as to why one's intercultural sensitivity would develop through these components or how to develop it.

Besides the findings from the literature, practice shows that hardly any Dutch HEI has implemented effective internationalisation activities to develop students' intercultural sensitivity. This study therefore focuses on the design and testing of an intercultural learning intervention at ASIS' home campus to develop students' intercultural sensitivity towards an ethnorelative view. The overarching research question in this study therefore is: How can students' intercultural sensitivity be developed?

\section{The Creative Action Methodology pedagogy: an alternative perspective}

The seeming gap in current studies of providing an understanding, "Verstehen," of influences of intercultural sensitivity development triggered the search for an alternative angle for this study. This angle comes from the Creative Action Methodology (CAM), which is a pedagogical approach. The CAM pedagogy's underlying theory provides a potential understanding of intercultural sensitivity development. This theory concerns the bridging of the observed discrepancy between nature, in CAM meaning the functioning of our brain, and nurture, in CAM meaning how people in the Netherlands are educated (Delnooz and de Vries 2018). As Delnooz and de Vries (2018) explain, CAM rests on two principles:

1. Our brains are not made to learn by heart, but instead to survive by solving problems.

2. Schools in the Netherlands instil a culture of the truth as students learn there is only one correct answer to a question.

(Delnooz and de Vries, 2)

The first principle of CAM stresses that when students are solely engaged in rote learning it reduces their motivation to learn and, in fact, triggers "oppositional behaviour" (Delnooz and de Vries 2018, 2 ). The second principle stresses that Dutch education's culture of the truth "conflicts with our brains" (2) as it impedes problem solving for which our brain is made (Delnooz 2008; Delnooz et al. 2012).

The CAM pedagogy builds on the work of Lunenberg, Ponte, and van de Ven (2007). Lunenberg et al. found that in Dutch education the Research Development and Diffusion model prevails in which it is assumed that knowledge can be generated objectively, is considered free of doubt, and which learners must learn by heart (Delnooz et al. 2012). While CAM focuses on a culture of the truth in a Dutch context, studies show that a culture of the truth is also prevalent in other countries such as the United Kingdom (Beere 2020; National Advisory Committee 1999) and the United States (Robinson and Aronica 2018). CAM's knowledge perspective builds on the work of authors including those critical theorists pertaining to the 'Frankfurt School,' such as Habermas. 
The CAM pedagogy consists of seven parameters to have learners break away from a culture of the truth. These are: conceptual thinking, using practical cases or problems, the application of a questioning method in class, offering advice to learners, using in-class discourse, and giving students the freedom and responsibility to choose (Delnooz 2008; Delnooz et al. 2012). These parameters form a class' mental structure in CAM (Delnooz et al. 2012, 58).

Numerous experiments with CAM at all levels of Dutch education show that learners at first resisted to work according to CAM's parameters and/or they were confused by them (Delnooz 2008; Delnooz et al. 2012). Learners resisted the idea that there are multiple truths and learners wanted to get certainty from their teachers that only one answer could be the correct answer (Delnooz 2008; Delnooz et al. 2012). Once learners' resistance and/or confusion was overcome to break away from a culture of the truth, learners were reported to develop an investigative and open attitude while they developed their critical and analytical thinking skills as well as their creative capabilities (Delnooz et al. 2012).

\section{A new approach to intercultural sensitivity development}

CAM's theory helps to theorise why people would engage cultural differences through an ethnocentric view by tendency: If the impact of a culture of the truth is that learners are impeded to be open to multiple perspectives this would also prevent learners to question their worldview. In other words, what seems to impede the development of learners' intercultural sensitivity during a learning intervention is the application of a pedagogical approach that shares characteristics pertaining to a culture of the truth.

The theory of CAM thus potentially provides a more fundamental explanation, "Verstehen," of intercultural sensitivity development: It is theorised that when learners break away from a culture of the truth, they develop a more open mind-set that contributes to their intercultural sensitivity development. A key condition of this development is for learners to overcome their resistance and/or confusion in order to break away from a culture of the truth. Figure 1 illustrates these ideas.

Following these ideas this study tests the impact of an intercultural learning intervention that is specifically aimed to bridge the discrepancy between nature and nurture, using CAM, to develop learners' intercultural sensitivity towards an ethnorelative view. 
Figure 1. Theoretical model of intercultural sensitivity development based on the theory of the Creative Action Methodology pedagogy.

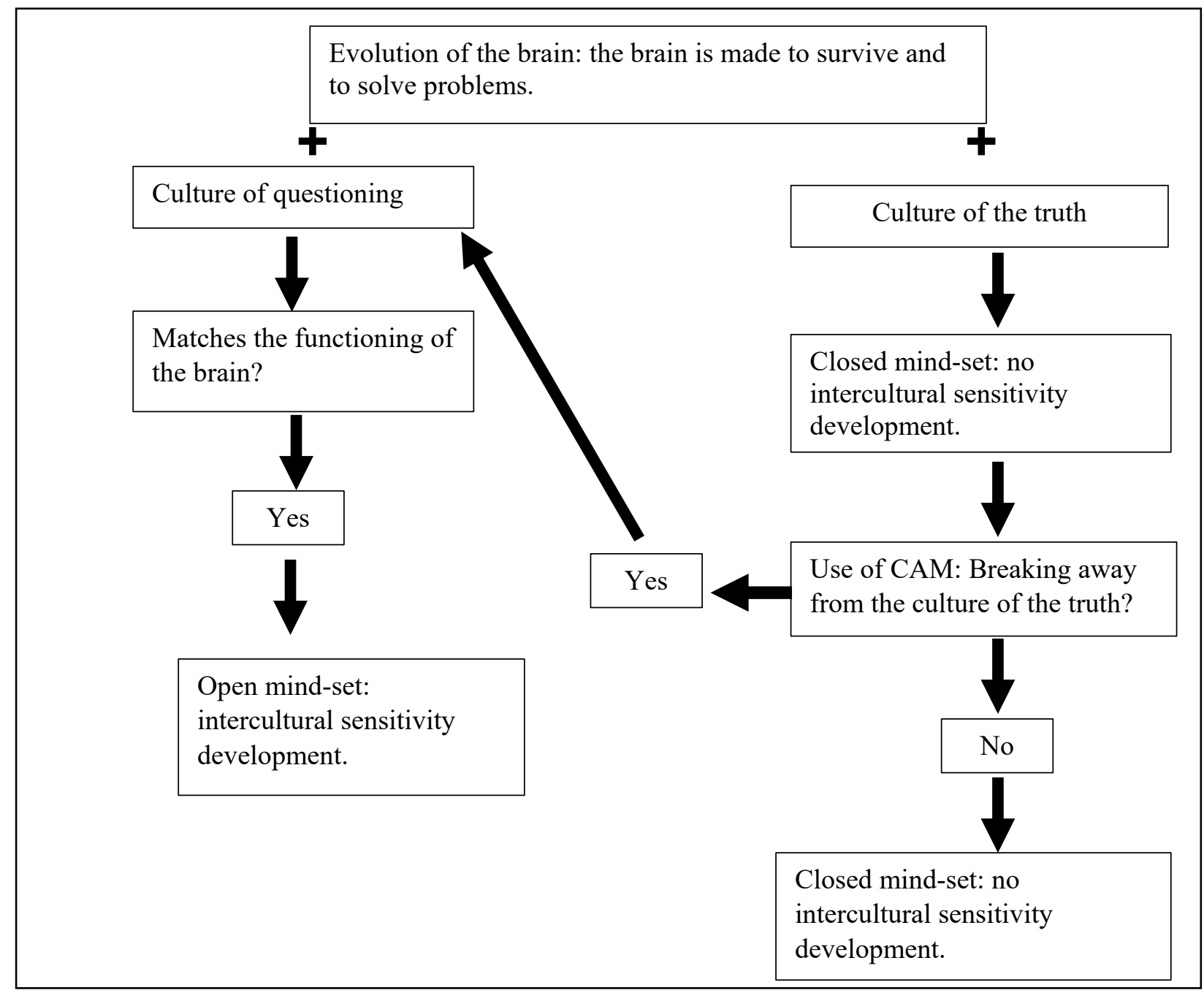

\section{METHODOLOGY}

The methodology employed in this study is Technical Action Research (TAR). As the ultimate aim of science is theory (Cohen, Manion, and Morrison 2011) the choice was made to apply TAR in an augmented way by examining whether the CAM pedagogy has pragmatic validity as a heuristic tool for intercultural sensitivity development.

\section{The intercultural learning intervention}

The Action Model of Intercultural Sensitivity and Competence Development, illustrated in figure 2, shows the blueprint for the intercultural learning intervention. The shape of this model resembles the Process Model of Intercultural Competence by Deardorff (2006). The top of the Action Model shows an iterative process between 'knowledge, comprehension, and conditions and attitude' to 'overcome resistance/confusion' to break away from a culture of the truth. This process is iterative because as previous research with CAM shows, students develop their critical, analytical, and creative skills as they learn to break away from a culture of the truth (Delnooz 2008; Delnooz et al. 2012).

As is portrayed in figure 2, as one learns to break away from a culture of the truth, they will become more open, investigative, and respectful, seeking multiple perspectives while also 
considering and valuing perspectives that differ from their own. As the bottom of figure 2 shows this process contributes to creating a more open mind-set to different worldviews which helps to develop one's intercultural sensitivity.

Figure 2. Action model of intercultural sensitivity and competence development

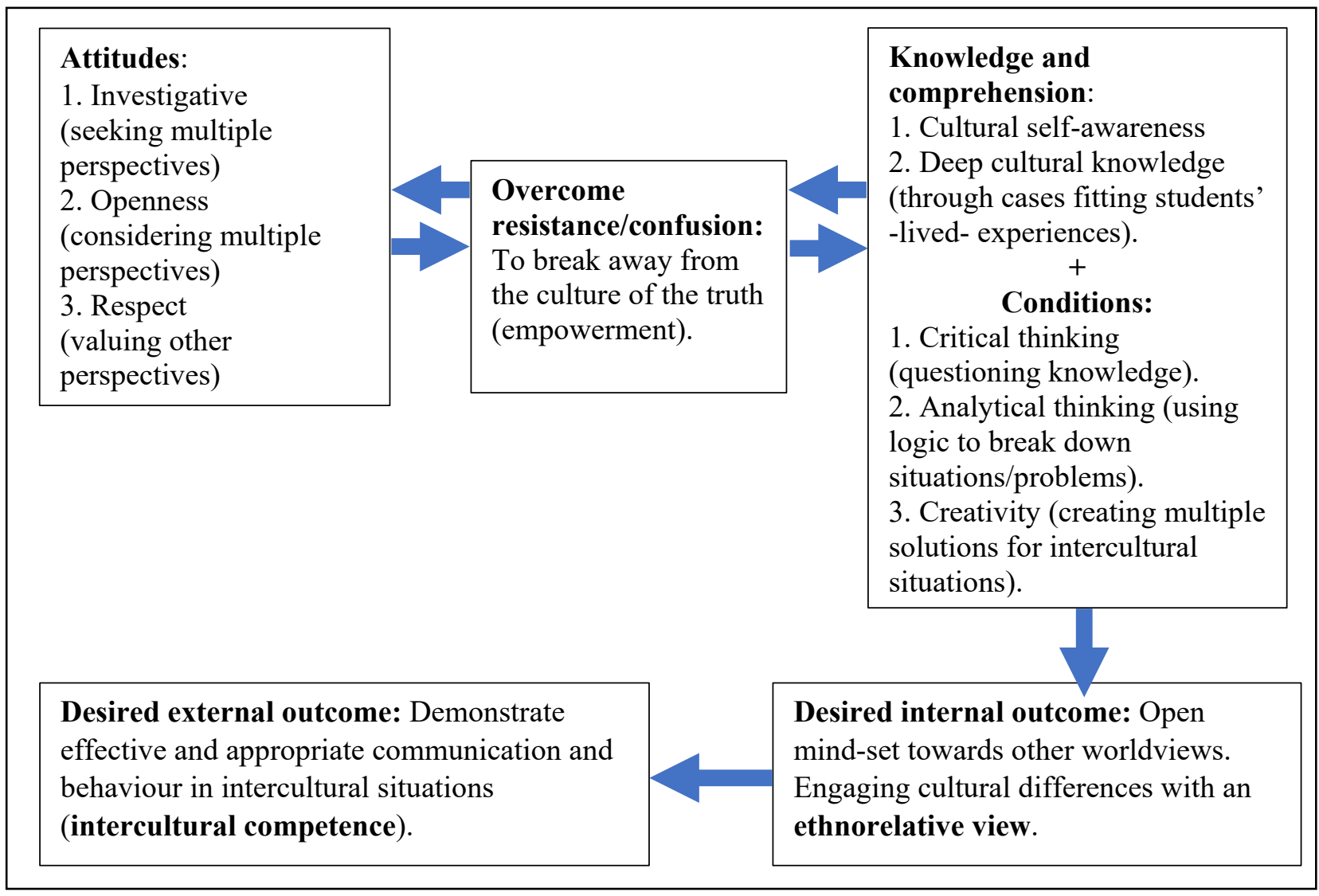

Action research supports emancipation (Cohen, Manion, and Morrison 2011). In this TAR emancipation signifies that learners become empowered to break away from a culture of the truth. Empowerment means that learners develop their intercultural sensitivity as they learn to handle multiple perspectives for intercultural situations, choosing a perspective using arguments with evidence, and creating solutions for such situations.

\section{Set-up of the intercultural learning intervention}

There are five key aims for the intercultural learning intervention:

1. Students gain deep knowledge of cultural values and behaviours to become more aware of relevant cultural differences.

2. Students question knowledge, consider multiple perspectives and make logical breakdowns of intercultural (business) cases to develop their critical and analytical thinking skills.

3. Students critically reflect on cultural values and behaviours to perceive values and behaviours from other cultures as equally viable.

4. Students engage in discourse to develop a more investigative, open, and respectful attitude towards cultural differences.

5. Students develop their creative skills by designing multiple solutions for intercultural (business) cases that consider relevant cultural differences. 
The lesson programme for the intercultural learning intervention consists of four sessions that each lasted approximately 2.25 hours (see appendix A). As knowledge was not treated as a fixed truth in these sessions, in-class discourse was a crucial component to question knowledge and to analyse intercultural situations from multiple perspectives.

\section{Research design}

A quasi-experimental design, thus without any control group, was deemed fitting for this study because the intercultural learning intervention was to be implemented within the normal school conditions of the students.

\section{Sample}

For this study 22 students overall participated in the quantitative part and of this group 20 also participated in the qualitative part. Purposive sampling (Cohen, Manion, and Morrison 2011) was applied on first-year business students from ASIS. All students in the study were Dutch nationals, born and raised in the Netherlands. A reason for this purposive sample is that findings from the literature suggest that members of marginalised groups are quicker in developing their intercultural competence than members of the dominant group (King, Baxter Magolda, and Massé 2011).

\section{Methods and procedures}

A mixed-methods approach, specifically a sequential explanatory strategy (Creswell 2009) was applied to analyse the data.

\section{Quantitative method}

The Intercultural Development Inventory (IDI) was used to measure participants' intercultural sensitivity prior to the intervention and after the intervention. The IDI is theoretically grounded in Milton Bennett's (1993) Developmental Model of Intercultural Sensitivity, and it assesses one's perception and experience of differences and similarities across cultures (Hammer 2011). The IDI provides a score of one's Developmental Orientation (DO) (Hammer 2009). The DO is one's primary orientation to cultural differences and similarities according to the IDI (Hammer 2009).

Through the DO pre-test and post-test scores a paired samples t-test in SPSS was run to provide insights whether there were any changes in participants' intercultural sensitivity. A regression analysis was also conducted to examine whether there was a positive trend in participants' DO scores.

\section{Qualitative method}

Semi-structured interviews, each lasting approximately 30 minutes, were conducted with 20 participants to examine whether participants' responses in the interviews showed that they were able to start breaking away from a culture of the truth. This would then form an explanation, "Verstehen," why participants either had or had not developed their intercultural sensitivity as shown by their DO scores. Therefore, it was deemed that thematic analysis was suitable for this purpose in which CAM functioned as the "fixed frame" (Ragin and Amoroso 2019, 68). Using CAM as the fixed frame, it was investigated whether students' interview responses about their experiences of the intervention met criteria pertaining to resistance, confusion, or empowerment regarding breaking away from a culture of the truth. 
As discussed in the introduction section, the CAM theory and previous research findings with CAM showed that this pedagogy initially leads to resistance and/or confusion among most learners before they become empowered to break away from the culture of the truth (Delnooz 2008; Delnooz et al. 2012; Delnooz and de Vries 2018). Therefore, it was analysed whether students' responses in the interviews about their experiences of the intervention met the criteria of resistance, confusion, or empowerment regarding breaking away from the culture of the truth. Three "a priori themes" (Ryan and Bernard 2003, 88) were put in place for the analysis and were used to code the responses. These a priori themes were:

1) The arise of resistance: Did the intervention at first instance lead to indications of resistance among participants to break away from the culture of the truth?

2) The arise of confusion: Did the intervention at first instance lead to indications of confusion among participants to break away from the culture of the truth?

3) The arise of empowerment: Did the intervention lead to indications of empowerment among participants to break away from the culture of the truth?

Along with the thematic analysis participants were classified twice. Once for how they experienced the beginning of the intervention and once for how they experienced the end of the intervention. This classification was also quantitatively analysed: Participants who were classified in the resistance phase were given a score of one while those who were classified in the confusion phase were given a score of two. Participants who were classified in the empowerment phase were given a score of three. The value given for participants' experience of the beginning of the intervention is called Score A while Score B represents participants' experience of the end of the intervention. Subtracting Score A from B offered an indication of any development in participants' ability to break away from a culture of the truth.

The focus of the quantitative and qualitative research in this study is on the group of participants rather than on each individual participant. This is in line with previous research conducted by Delnooz (2008) and Delnooz et al. (2012) in which the focus was on the development of groups of learners through the application of CAM. Focusing on groups of learners rather than on individual learners serves the purpose of this TAR to determine whether CAM has theoretical and statistical significance as a heuristic tool. Therefore, no further investigation took place on the individual scores of students in this study.

\section{Ethics}

To reduce and prevent potential risks to the research participants students were informed about the study and given the opportunity to participate through a Participant Information Sheet and a Participant Consent Form. Students were invited to fill out the IDI questionnaire and they were invited for an interview. Participation was voluntary. In total, 22 students completed the IDI questionnaire. Out of this group of participants, 20 students agreed to be interviewed. The first author of this article conducted the interviews and conducted the coding for the interview analysis. None of the authors of this article were involved in any other educational activities with the students who participated in this study. This was to further reduce any potential risk to participants and to avert coercion to participate in the questionnaire and/or interview. Students were also informed that they could withdraw from the study at any time without any reason. 


\section{FINDINGS}

\section{Quantitative findings}

The quantitative findings are presented using a paired samples $t$-test and a regression analysis. The paired samples t-test provided insights on whether there were any changes in participants' intercultural sensitivity after the intercultural learning intervention. The regression analysis functioned to determine if there is a positive trend in participants' scores obtained from the IDI and whether this has statistical significance.

\section{Paired samples t-test}

Table 1 reports the change in participants' DO mean scores. Participants' DO mean score in the pre-test was 83.55. This score falls within the Polarisation orientation, specifically, a Defense orientation, on the Intercultural Development Continuum (IDC). This is an orientation by which one approaches cultural differences with a sense that one's worldview is superior to others and that other cultures are considered a threat (Hammer 2012, 121).

Table 1 reports a DO mean score of 88.18 in the post-test. This score falls within the Minimisation orientation on the IDC. Minimisation represents a stage between the ethnocentric and ethnorelative orientations and means that one no longer sees other cultural values as threatening to one's world view (Hammer 2009).

Table 1. Paired samples t-test on participants' DO mean scores

\begin{tabular}{|c|c|c|c|c|c|}
\hline & \multicolumn{2}{|l|}{$\begin{array}{l}\text { Ethnocentric } \\
\text { orientations }\end{array}$} & \multirow{2}{*}{$\begin{array}{l}\text { Transition } \\
\text { orientation } \\
\text { Minimisation }\end{array}$} & \multicolumn{2}{|l|}{$\begin{array}{l}\text { Ethnorelative } \\
\text { orientations }\end{array}$} \\
\hline Orientation & Denial & $\begin{array}{l}\text { Polarisation } \\
\text { (Defense/ } \\
\text { Reversal) }\end{array}$ & & Acceptance & Adaptation \\
\hline Score range IDI & $55-69.99$ & $70-84.99$ & $85-114.99$ & $115-129.99$ & $130-145$ \\
\hline $\begin{array}{l}\text { D0 mean score pre- } \\
\text { test }\end{array}$ & & 83.55 & & & \\
\hline $\begin{array}{l}\text { D0 mean score } \\
\text { post-test }\end{array}$ & & & 88.18 & & \\
\hline $\begin{array}{l}\text { Standard } \\
\text { deviation }\end{array}$ & & $(10.81)$ & $(12.31)$ & & \\
\hline Change & $t(d f=21)$ & $\mathbf{R}$ & $P$-value & & \\
\hline 4.63 & -2.219 & 0.65 & 0.038 & & \\
\hline
\end{tabular}

Note: $\mathrm{N}=22 . \mathrm{DO}=$ Developmental Orientation.

The findings from the Paired Samples t-test show that the change in the research participants' DO mean scores has a significance value of $\mathrm{p}=0.038(\mathrm{n}=22$; Paired-Samples t-test: Mpre $=83.55, \mathrm{SD}=10.81 ;$ Mpost $=88.18, \mathrm{SD}=12.31$ ). This result is meaningful because although the sample size and the number of intercultural sessions were small in number, the intervention did have a positive impact on students' intercultural sensitivity. As table 1 shows this impact is statistically significant. Therefore, from the Paired Samples t-test the conclusion can be drawn that the CAM pedagogy has theoretical and statistical significance. This confirms that CAM can be used as a heuristic tool to develop students' intercultural sensitivity. 


\section{Regression analysis}

The results of the regression analysis shows that there is a positive effect on research participants' DO scores after the intervention $\left(\mathrm{R}^{2}=0.42\right.$; Adjusted $\mathrm{R}^{2}=0.39 ; \mathrm{t}=3.81$; df $1=1$; df2 = $20 ; \mathrm{p}=0.001)$. Given the small sample the adjusted $\mathrm{R}^{2}$ was calculated in SPSS. It shows that, on average, there is an increase in the DO scores. This increase is not coincidental as $\mathrm{p}=0.001$. This statistically significant result suggests that the participants' DO scores will continue to increase if participants participate in more intercultural sessions using CAM.

Figure 3. Participants' Developmental Orientation scores before ( $\mathrm{x}$-axis) and after (y-axis) the intervention.

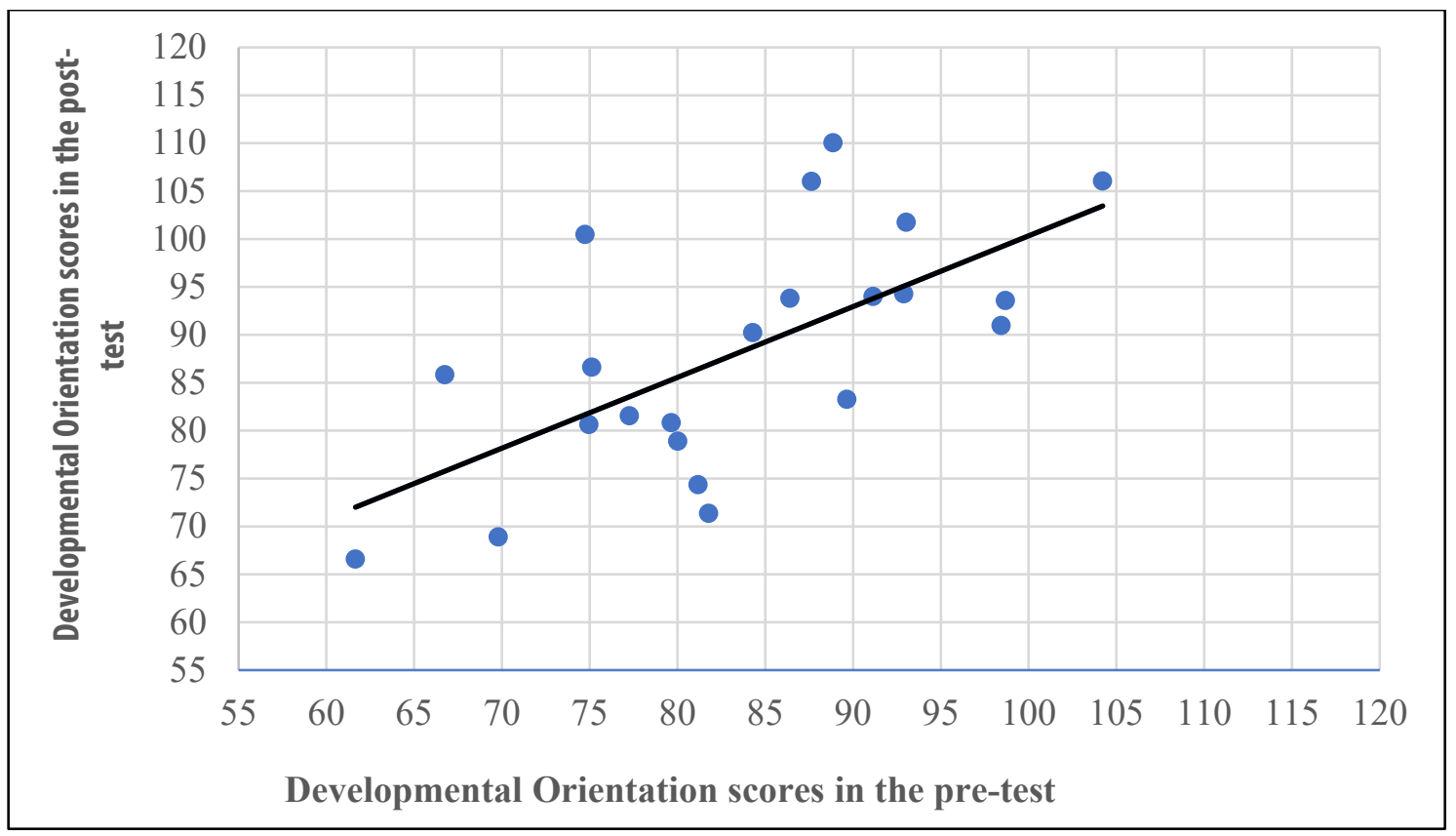

$\mathrm{N}=22 ; \mathrm{R}^{2}=0.42 ;$ adjusted $\mathrm{R}^{2}=0.39 ; \mathrm{t}=3.81 ; \mathrm{df} 1=1 ; \mathrm{df} 2=20 ; \mathrm{p}=0.001$. The graph was created in Excel. The adjusted $\mathrm{R}^{2}$ was calculated in SPSS.

\section{Qualitative findings}

To gain an in-depth understanding of the process of breaking away from a culture of the truth during the intervention an analysis was made of participants' experiences of the intervention.

\section{Interview results}

Participants' interview responses that were typical of either resistance, confusion, or empowerment were analysed. Based on the interview responses participants were classified twice: Once for how they experienced the beginning of the intervention and once for how they experienced the end of the intervention. There were 20 participants who agreed to be interviewed. Their classifications are shown in table 2. Interviewees are given a code from S01 (student 1) to S20 (student 20). 
Table 2. Participants' classification and scoring on breaking away from a culture of the truth

\begin{tabular}{|c|c|c|c|c|c|c|c|c|}
\hline \multicolumn{3}{|c|}{$\begin{array}{l}\text { Classification and scoring of participants } \\
\text { based on their experiences of the } \\
\text { beginning of the intervention on breaking } \\
\text { away from a culture of the truth }\end{array}$} & \multirow[t]{2}{*}{$\begin{array}{l}\text { Score } \\
\text { A }\end{array}$} & \multicolumn{3}{|c|}{$\begin{array}{l}\text { Classification and scoring of participants } \\
\text { based on their experiences of the end of } \\
\text { the intervention on breaking away from } \\
\text { a culture of the truth }\end{array}$} & \multirow[t]{2}{*}{$\begin{array}{l}\text { Score } \\
\text { B }\end{array}$} & \multirow{2}{*}{$\begin{array}{l}\text { Change } \\
\text { in } \\
\text { score } \\
\text { B - A }\end{array}$} \\
\hline Res. (1) & $\begin{array}{l}\text { Conf. } \\
\text { (2) }\end{array}$ & Emp. (3) & & $\begin{array}{l}\text { Res. } \\
\text { (1) }\end{array}$ & $\begin{array}{l}\text { Conf. } \\
\text { (2) }\end{array}$ & Emp. (3) & & \\
\hline S04 & & & 1 & S04 & & & 1 & 0 \\
\hline S20 & & & 1 & S20 & & & 1 & 0 \\
\hline S03 & & & 1 & & S03 & & 2 & +1 \\
\hline S02 & & & 1 & & & S02 & 3 & +2 \\
\hline S05 & & & 1 & & & S05 & 3 & +2 \\
\hline S07 & & & 1 & & & S07 & 3 & +2 \\
\hline \multirow[t]{14}{*}{ S16 } & & & 1 & & & S16 & 3 & +2 \\
\hline & S06 & & 2 & & & S06 & 3 & +1 \\
\hline & S08 & & 2 & & & S08 & 3 & +1 \\
\hline & S09 & & 2 & & & S09 & 3 & +1 \\
\hline & S10 & & 2 & & & S10 & 3 & +1 \\
\hline & S11 & & 2 & & & S11 & 3 & +1 \\
\hline & S12 & & 2 & & & S12 & 3 & +1 \\
\hline & S14 & & 2 & & & S14 & 3 & +1 \\
\hline & S15 & & 2 & & & $S 15$ & 3 & +1 \\
\hline & S17 & & 2 & & & S17 & 3 & +1 \\
\hline & S18 & & 2 & & & S18 & 3 & +1 \\
\hline & S19 & & 2 & & & S19 & 3 & +1 \\
\hline & & S01 & 3 & & & S01 & 3 & 0 \\
\hline & & S13 & 3 & & & S13 & 3 & 0 \\
\hline \multicolumn{3}{|c|}{ Total score } & 35 & & & & 55 & \\
\hline \multicolumn{3}{|c|}{ Average score } & 1.75 & & & & 2.75 & +1.00 \\
\hline
\end{tabular}

Note: 20 participants were classified based on their interview responses. Res. $=$ Resistance; Conf. $=$ Confusion; Emp. = Empowerment. For Resistance, Confusion, and Empowerment respectively 1, 2, and 3 points are given. $S=$ Student.

Table 2 shows that based on interview responses most interviewees, 18 out of 20, were initially classified as showing signs of either resistance or confusion. This particular finding is coherent with research conducted with CAM prior to this intervention in which it was found that learners tend to initially resist and/or be confused when they have to break away from the culture of the truth. Table 2 also shows that most interviewees, 17 out of 20 , were eventually classified as showing signs of empowerment on breaking away from a culture of the truth. This finding is also in accordance with prior research with CAM.

Interviewees' responses were analysed to assess if and to what degree students had developed in breaking away from a culture of the truth. As explained in the methodology section interviewees were given codes in the form of scores for each of their classifications: As table 2 shows participants' average score for Score A was 1.75, out of a maximum of 3, while participants' average score for Score B was 2.75, out of a maximum of 3. Thus, the average change in participants' scores was 1 point or $57.14 \%(1 / 2.75=57.14 \%)$. 
This development in students' classifications is meaningful. It suggests that the intervention has set the emancipatory process in motion to empower students to break away from a culture of the truth. This result confirms the statistically significant growth found in participants' intercultural sensitivity as measured through the IDI. Overall, this confirms that CAM has pragmatic validity as a heuristic tool to develop students' intercultural sensitivity.

\section{Thematic analysis of interviewees' responses}

Participants' experiences were analysed based on their interview responses indicating either signs of resistance, confusion, or empowerment towards breaking away from a culture of the truth. Three main themes arose from the interview analyses. Theme 1 is resistance to consider multiple perspectives. Theme 2 is confusion. This theme consists of two sub-themes, namely: difficulty in engaging in critical and analytical thinking and difficulty with creating practical solutions. Theme 3 is empowerment. This theme consists of two sub-themes, namely: able to handle multiple perspectives and able to create practical solutions.

Theme 1: Resistance to considering multiple perspectives. Table 2 shows that 12 out of 20 interviewees were initially classified as showing resistance towards breaking away from a culture of the truth. For four of these participants, who came to show indications of empowerment, this resistance was particularly occurring during the earlier sessions as became clear from their responses. From interviewees' responses it became clear that they had the need of wanting to have the correct answer in class to solve a particular intercultural case. Probing participants on this point revealed that participants also had this need for wanting the correct answer in other classes at ASIS.

The second form by which (initial) resistance to consider multiple perspectives among the participants became clear from the interviews was that students indicated that, especially during the first couple of sessions, they disliked in-class discourse. One participant (S02) considered in-class discourse as "frustrating" while S03 explained to dislike having to think deeper about their perspectives and having to explain this.

Theme 2: Confusion. Of the 20 interviewees, 11 were initially classified as showing confusion towards breaking away from a culture of the truth. From their responses two sub-themes emerged.

Sub-theme 2.1: Difficulty engaging in critical and analytical thinking. Participants stated that they felt challenged, especially in sessions one and two, to choose and to argue for one perspective. As S08 stated: "I think [selecting one perspective] was quite difficult [...] I really could not stick to one actually ...” S18 shared:” Sometimes it was really hard because I thought there could be more explanations possible and [...] You have to find a clear explanation behind your ... explanation. That can also be really hard."

Sub-theme 2.2: Difficulty with creating practical solutions. Participants' responses also indicated the difficulty they had had with creating practical solutions. Participants shared that they tried to consider different cultural perspectives that could play a role in the intercultural cases when designing solutions and that they used the intercultural literature to do this. For participants this made the assignment complex in the earlier sessions. As S17 stated:

Ifound that pretty difficult. Yeah. Because uh ... although you got several perspectives and you could do research it is always a ... uh ... tricky thing to try to come up with a solution that is appropriate for another culture or for someone else ... 
Theme 3: Empowerment. Table 2 shows that 17 out of 20 interviewees, were classified as showing indications of empowerment towards breaking away from a culture of the truth. Two subthemes emerged from these interviewees' responses.

Sub-theme 3.1: ability to handle multiple perspectives. The afore-mentioned 17 participants indicated that through the four intercultural sessions they had learned about cultural differences and the impact that these can have on intercultural encounters. Six of these participants, without being prompted for this, discussed that through the sessions they started reflecting on different cultural perspectives in their daily lives. As S01 shared:" [The sessions] made me think a lot [...] So I started to think a lot about what are really the cultural differences between some countries and even within one country." S05 even stated that the sessions formed an inspiration to conduct research in anticipation of a trip abroad to gain an understanding of the local culture.

From participants' responses it also became clear that two components of the intervention triggered participants in becoming aware of cultural differences and in learning to handle multiple perspectives. These components were conducting research on the intercultural literature and using in-class discourse. Students stated that through the research and class discussions they became aware of various cultural perspectives and their impact at a more profound level.

All 17 participants classified as showing indications of empowerment had enjoyed in-class discussions as it helped them to better focus and learn. Moreover, participants appreciated that their ideas were not judged negatively in class. Finally, participants liked the fact that they could also learn from each other instead of only from the teacher.

Sub-theme 3.2: ability to create practical solutions. Participants indicated that as the sessions progressed, it became easier to create solutions for intercultural situations. Specifically, all seventeen participants who were classified as showing indications of empowerment shared that they noticed a development in their ability to create solutions. Moreover, from participants' interview responses it became clear that students enjoyed creating solutions. To illustrate, S06 stated: "I liked actually thinking about [solutions] [...] I think I enjoyed doing that because I was like discovering new ways of solving the problem." Similarly, S17 shared: "I think gradually it got better, like I . . quicker in thinking about these situations and uh finding solutions, because I just became more aware of the different viewpoints and the different cultures ..."

The findings from the thematic analysis show that, overall, the emancipatory process was set in motion among participants to break away from a culture of the truth: Most students started to show signs of empowerment.

\section{DISCUSSION}

The central research question of this study is 'How can students' intercultural sensitivity be developed?' In response to this question an intercultural learning intervention was set up for first year local students of HE in the Netherlands using the CAM pedagogy. The findings of this study are promising: Results from the paired samples t-test and the regression analysis show that in the context of this TAR the CAM pedagogy has pragmatic validity, with statistical and theoretical significance, as a heuristic tool for intercultural sensitivity development. There are a few participants whose IDI scores did not increase. Yet, the Paired Samples t-test and the regression analysis provide strong indications that, overall, a start has been made in developing students' intercultural sensitivity in this TAR. Importantly, the qualitative findings from the thematic analysis suggests that breaking away from a culture of the truth forms an explanation with a more fundamental understanding of intercultural sensitivity development. 
This more fundamental understanding, "Verstehen," clarifies why, on average, participants' intercultural sensitivity had developed during this TAR: Participants' intercultural sensitivity developed as the emancipatory process was set in motion among participants to break away from a culture of the truth. As described by Delnooz and De Vries (2018) in this process the discrepancy between nature, the functioning of our brain to solve problems, and nurture, the impact of the culture of the truth, which conflicts with the functioning of our brain, is being bridged.

The results of this TAR show that this process created in general a more open mind-set among participants to handle multiple perspectives. This finding is in line with previous research that was conducted with CAM by Delnooz (2008) and Delnooz et al. (2012). Thus, this study shows that it is especially important to apply an effective pedagogical approach in which knowledge is questioned to develop students' intercultural sensitivity. In this respect this study differs from previously published research on intercultural sensitivity and competence development. Specifically, while studies such as those from Demetry and Vaz (2017), Mellizo (2017), and Behrnd and Porzelt (2012) focused on developing students' intercultural sensitivity and/or competence, no explicit emphasis is placed in these studies on the pedagogical approach to develop this.

As the results of this study show, the emancipatory process of breaking away from a culture of the truth is characterised by a move from resistance or confusion towards empowerment. This finding is in line with previous findings by Delnooz (2008) and Delnooz et al. (2012). The three themes with sub-themes analysed in the qualitative findings section showed that most participants in this TAR initially showed resistance or confusion towards breaking away from the culture of the truth during the intervention. Yet, towards the end of the intervention students came to show signs of empowerment in this TAR.

Starting with theme 1 , resistance, responses of students in this TAR showed signs of the impact that a culture of the truth can have on students. As explained by Delnooz et al. (2012) when teachers instruct learners that there is only one correct way to approach a question this stifles learners' critical and analytical thinking abilities. Interview responses from participants indicated that this was also the case during this TAR as students resisted to consider multiple perspectives. S04, for instance, stated that "[One option] is more easier and you can just focus on one and if you learn that it is just fine [...] It is easier to remember I guess."

These responses appear to be an indication that a culture of the truth as described by Delnooz (2008), Delnooz et al. (2012) and Delnooz and de Vries (2018) is prevalent in ASIS' programme. This idea is further supported by the observation that students in their interview responses shared that they had to get used to the CAM pedagogy: Participants' responses suggest that before this TAR students at ASIS were hardly ever put to the task of engaging in critical and analytical thinking. To illustrate, S04 shared with me that in other classes they were used to receiving information and having to merely absorb this information. S02 stated that:

We don't really get asked why we think anyway in this ... programme [...] There is a lot of ... like this is what you learn and this is how you do it and I think this is the first time that we have like interaction and your own opinion as well ...

This finding confirms previous findings by Delnooz (2008) and Delnooz et al., (2012), Lunenberg, Ponte, and van de Van (2007), and Verschuren (2002) that critical and analytical thinking is hardly ever applied at schools in the Netherlands. This phenomenon is however not only confined to the Dutch educational context. Authors like Robinson and Aronica (2018) and Beere (2020) have recently reiterated their call for changes in pedagogy in the United States and UK 
emphasising the importance of developing creative and curious learners who can think critically and analytically to become resilient in a changing world. Therefore, the use of CAM pedagogy to help students move away from the idea that there is a fixed truth can serve other pedagogical purposes as well, including the development of social and emotional competences, social awareness, selfawareness, self-management, and decision-making skills.

Theme 2 concerned confusion. Responses in this theme showed that students were initially confused by having to make a well-argued choice for one perspective out of several perspectives. S09 described this activity as:

A little bit more difficult because now you don't have something to choose from. Now you need to think of like something completely ... on your own and keep in mind ... the cultural aspects and then think of a good solution. So it was a little bit more difficult for me just because there were no like ... pre-set choices you had to think of everything yourself, but you know that is what you do if you are a consultant...

Theme 3 concerns empowerment. Students' responses that were categorised to this theme show that, through this TAR most students started to break away from a culture of the truth at ASIS. Interestingly, students' responses showed that having in-class discussions helped students to become empowered to break away from a culture of the truth. Some participants explained that they can better learn through a conversation with someone about a topic as it is more effective for them compared to when they only must sit and listen. The following quote from S07 illustrates that:

To hear not only your perspective on how you think of that situation [but] also others was for me uh ... something that you can learn from because you can take that into consideration and actually see ... A thing or a situation from a different perspective I think. How they see it. I get why they react that way or this way.

This finding is in line with Hattie and Yates (2014) on effective learning techniques. Moreover, some participants had indicated that they enjoyed in-class discourse because perspectives were not judged negatively nor that students were restricted in their thinking. As S15 commented:
I think it is important that everyone's opinion is valued and that there should not be too much critics ... critique about it because I think that when you just let someone talk and uh... not directly say like 'well because... you have to look at it differently because on the exam we want you to write it in this way,' but maybe like keep that for a later stage, but when you start at the beginning just letting people talk and ... uh get to know how they think then it is much more interesting to ... see how ... cultural differences work because if we immediately have to think in a certain schedule then there are already a set of boundaries...

In addition, several participants argued that using multiple perspectives, regardless of the subject at hand, would help them to create better solutions or it would help them to choose the most effective way to tackle a problem. This finding is in line with the first principle of CAM that the human brain is not made for mere rote learning, but for solving problems (Delnooz and de Vries 2018). This finding is also in line with Robinson and Aronica (2018) and Beere (2020) who emphasise the importance of developing learners' critical and creative capabilities as this facilitates the process of teaching new knowledge and skills to the students. 
Following the findings from this study on the development of students' intercultural sensitivity using the CAM pedagogy, it appears that this TAR fills a gap in the current body of literature on intercultural sensitivity development at schools' home campuses: In current studies, such as Gordon and Mwavita (2018), Young, Haffeejee, and Corsun (2017), and Tirnaz and Narafshan (2018) statistical explanations are given concerning the development of students' intercultural sensitivity and/or competence. Yet, these studies lack a fundamental theoretical explanation for this. Moreover, in no other studies on intercultural sensitivity or competence development is a combination of parameters similar to CAM applied for an intercultural learning intervention. To illustrate, in studies by Altshuler, Sussman, and Kachur (2003), López-Rocha and Vailes (2017), and Behrnd and Porzelt (2012) knowledge is treated as a truth as participants in these studies were not encouraged to question it.

Thus, a contribution from this study to the current literature is also the explicit focus on the pedagogical approach to be used in an intercultural learning intervention. As stated in the results section, CAM as the applied pedagogy appears to be the cause of learners' intercultural sensitivity development in this TAR.

\section{CONCLUSION}

The findings from this study answer the research question 'How can students' intercultural sensitivity be developed?' The answer is that it can be developed by using the CAM pedagogy. More specifically, intercultural sensitivity can be developed by having students break away from a culture of the truth. While most studies explain human behaviour by nature or by nurture, this TAR examines it by combining both theoretical points of view. This is new.

Given the results of this TAR it appears that this combination is an effective heuristic tool. As this small-scale study was conducted at one school in the Netherlands only, it is worth it to pursue similar studies using CAM at other HEIs. This will help to determine the external as well as the ecological validity of this TAR (Cohen, Manion, and Morrison 2011). Further research is also warranted to check if in other educational contexts, besides the Dutch context, CAM is an effective heuristic tool. This is because, as has become apparent through the work of authors such as Robinson and Aronica (2018), the issue of a culture of the truth appears to be a more general issue. On that note it is worth pointing out that as the world is ever more globalising so are opposing truths ever more in a collision across the globe. Therefore, we believe that teachers play an important role in empowering students to embrace multiple truths. We suggest that the CAM pedagogy can contribute to this.

Jonathan van Melle has a Doctorate of Education from the University of Liverpool and currently works at the Avans University (NLD). His work focuses on internationalising HE programmes. He is a Professor of Intercultural Sensitivity.

Marco Ferreira has a PhD in Pedagogical Psychology. He is Professor of Education at ISEC Lisboa, Researcher at UIDEF/Institute of Education, and part-time Professor at FMH / University of Lisbon (PRT). 


\section{REFERENCES}

Altshuler, Lisa., Nan M. Sussman, and Elizabeth Kachur. 2003. "Assessing Changes in Intercultural Sensitivity Among Physician Trainees Using the Intercultural Development Inventory." International Journal of Intercultural Relations, 27: 387-401. https://doi.org/10.1016/S0147-1767(03)00029-4.

Australian Government. 2021. Australian Strategy for International Education 2021-2030. https://www.dese.gov.au/australian-strategy-international-education-2021-2030/resources/australianstrategy-international-education-2021-2030.

Beere, Jackie. 2020. The Complete Learner's Toolkit: Metacognition and Mindset-Equipping the Modern Learner with the Thinking, Social and Self-Regulation Skills to Succeed at School and in Life. Carmarthen, UK: Independent Thinking Press.

Behrnd, Verena, and Susanne Porzelt. 2012. "Intercultural Competence and Training Outcomes of Students with Experiences Abroad." International Journal of Intercultural Relations 36, no. 2: 213-23.

Bennett, Milton. J. 1993. “Towards Ethnorelativism: A Developmental Model of Intercultural Sensitivity." In Education for the intercultural experience, edited by R. Michael Paige, 21-72. Yarmouth, ME: Intercultural Press, Inc.

Bennett, Milton J. 2012. "Paradigmatic Assumptions and a Developmental Approach to Intercultural Learning." In Student Learning Abroad. What Our Students are Learning, What They're Not, and What We Do about It, edited by Michael Vande Berg, R. Michael Paige, and Kris Hemming Lou, 90-114. Sterling, VA: Stylus Publishing.

Bussemaker, Mariëtte. 2014. Government's Vision on the International Dimension of Higher Education and VET. (Letter No. IPC 2250). Retrieved from Government website:

https://www.government.nl/ministries/ministry-of-education-culture-andscience/documents/letters/2014/07/21/government-s-vision-on-the-international-dimension-of-highereducation-and-vet.

Cohen, Louis, Lawrence Manion, and Keith Morrison. 2011. Research Methods In Education. 7th ed. New York, NY: Routledge.

Creswell, John. W. 2009. Research Design. Qualitative, Quantitative, and Mixed Methods Approaches. 3rd Ed. Thousand Oaks, CA: Sage Publications, Inc.

Deardorff, Darla. K. 2006. "Identification and Assessment of Intercultural Competence as a Student Outcome of Internationalisation." Journal of Studies in International Education 10, no. 3: 241-66.

Delnooz Paul V. A. Creative Action Methodology: About Education, Research and the Art of Creative Thinking. 2008. Breda, the Netherlands: NHTV, Academic Studies.

Delnooz, Paul. V. A., and Eti W. de Vries. 2018. "How to Measure the Effectiveness of Teachers: Validation of an Instrument Based on the Creative Action Methodology." Pedagogy and the Human Sciences 6, no. 1: $1-14$.

Delnooz, P. V. A., Constance Janssen, Theo Pullens, Piet van Meer, and Nicole van Son. 2012. Over Creatieve Actie Methodologie en de Ontbrekende Schakel in Het Onderwijs: Op Weg Naar Kritische, Creatieve en Ondernemende Leerlingen en Studenten. De Theorie en Onderzoeksresultaten [On Creative Action Methodology and the Missing Link in Education: Towards Critical, Creative and Entrepreneurial Pupils and Students. Theory and Research Results]. City and publisher have been anonymised to ensure anonymity of the host organisation which is subject of this research.

Demetry, Chrysanthe, and Richard F. Vaz. 2017. "Influence of an Education Abroad Program on the Intercultural Sensitivity of STEM Undergraduates: A Mixed Methods Study." Advances in Engineering Education 6, no. 1, (Spring): 1-32.

de Wit, Hans. 2010. Internationalisation of Higher Education in Europe and its Assessment, Trends And Issues. PDF file. December.

https://people.utm.my/sanitah/files/2016/02/Internationalisation of Higher Education in Europe DE F_december_2010.pdf.

Eisenchlas, Susana, and Sue Trevaskes. 2007. "Developing Intercultural Communication Skills Through Intergroup Interaction." Intercultural Education 18, no. 5, December: 413-25. https://doi.org/10.1080/14675980701685271.

Gordon, Sarah. R., and Mwarumba Mwavita. 2018. "Evaluating the International Dimension in an Undergraduate Curriculum by Assessing Students' Intercultural Sensitivity." Studies in Educational Evaluation, no. 59: 76-83.

Hammer, Mitchell R., Milton J. Bennett, and Richard Wiseman. 2003. "Measuring Intercultural Sensitivity: The Intercultural Development Inventory." International Journal of Intercultural Relations 27, no. 4 (July): 42143. https://doi.org/10.1016/\$0147-1767(03)00032-4. 
Hammer, Mitchell R. 2009. "The Intercultural Development Inventory." In Contemporary Leadership and Intercultural Competence: Exploring the Cross-cultural Dynamics within Organizations, edited by Michael A. Moodian, 203-18. Thousand Oaks, CA: Sage.

Hammer, Mitchell. R. 2011. "Additional Cross-Cultural Validity Testing of the Intercultural Development Inventory." International Journal of Intercultural Relations 35, no. 4: 474-87.

Hammer, Mitchell R. 2012. "The Intercultural Development Inventory: A New Frontier in Assessment and Development of Intercultural Competence." In Student Learning Abroad. What Our Students Are Learning, What They're Not, and What We Do about It, edited by Michael Vande Berg, R. Michael Paige, and Kris Hemming Lou, 90-114. Sterling, VA: Stylus Publishing.

Hattie, John, and Gregory Yates. 2014. Visible Learning and the Science of How We Learn. New York, NY: Routledge.

Jon, Jae-Eun. 2013. "Realizing Internationalization at Home on Korean Higher Education: Promoting Domestic Students' Interaction with International Students and Intercultural Competence." Journal of Studies in International Education 17, no. 4: 455-70.

King, Patricia M., Marcia B. Baxter Magolda, and Johanna C. Massé. 2011. "Maximizing Learning from Engaging Across Difference: The Role of Anxiety and Meaning Making." Equity \& Excellence in Education 44, no. 4 (November): 468-87.

Knight, Jane. 2008. Higher Education in Turmoil: The Changing World of Internationalization. Rotterdam, the Netherlands: Sense Publishers.

López-Rocha, Sandra, and Fabienne Vailes. 2017. "Developing Intercultural Communicative Competence for the Year Abroad Experience." In Innovative Language Teaching and Learning at University: Enhancing Employability, edited by Carmen Álvarez-Mayo, Angela Gallagher-Brett, and Franck Michel, 67-75. Research-publishing.net. https://doi.org/10.14705/rpnet.2017.innoconf2016.656

Lunenberg, Mieke, Petra Ponte, and Piet-Hein van de Ven. 2007. “Why Shouldn't Teachers and Teacher Educators Conduct Research on Their Own Practices? An Epistemological Exploration." European Education Research Journal 6, no. 1: 13-24.

Mellizo, Jennifer. M. 2017. "Exploring Intercultural Sensitivity in Early Adolescence: A Mixed Methods Study." Intercultural Education 28, no. 6 (November): 571-90.

Ministry of Education Malaysia. 2013. Malaysia Education Blueprint 2013-2015 (Preschool to Post-Secondary Education). Retrieved from https://teachformalaysia.org/wp-content/uploads/2019/08/Preliminaryreport-Blueprint-English.pdf.

Moses, Jonathon W, and Torbjørn L. Knutsen. 2007. Ways of Knowing: Competing Methodologies in Social and Political Research. Basingstoke, UK: Palgrave Macmillan.

National Advisory Committee on Creative and Cultural Education. 1999. "All Our Futures: Creativity, Culture and Education." Accessed March 2018. http://sirkenrobinson.com/pdf/allourfutures.pdf.

Olson, Christa Lee, and Kent R. Kroeger. 2001. "Global Competency and Intercultural Sensitivity." Journal of Studies in International Education 5, no. 2 (June): 116-37. https://doi.org/10.1177/102831530152003.

Prieto-Flores, Òscar, Jordi Feu, and Xavier Casademont. 2016. "Assessing Intercultural Competence as a Result of Internationalization at Home Efforts: A Case Study from the Nightingale Mentoring Program." Journal of Studies in International Education 20, no. 4: 437-53.

Pusch, Margaret D. 2009. "The Interculturally Competent Global Leader." In The SAGE Handbook of Intercultural Competence, edited by Darla K. Deardorff, 66-84. Thousand Oaks, CA: Sage Publications, Inc.

Ragin, Charles C., and Lisa M. Amoroso. 2019. Constructing Social Research. The Unity and Diversity of Method. 3rd Ed. Thousand Oaks, CA: SAGE Publications, Inc.

Robinson, Ken, and Lou Aronica. 2018. You, Your Child and School: Navigate Your Way to the Best Education. UK: Penguin Random House, 2018.

Ryan, Gery W., and Bernard, H. R. 2003. Techniques to Identify Themes. Field Methods, 15(1), 85109. https://doi.org/10.1177/1525822X02239569.

Swedish Government Inquiries. 2018. Internationalisation of Swedish Higher Education and research. Accessed January 28, 2019.

http://www.government.se/48fc30/contentassets/4df6aeabd2bd4f5dbbf69210f786e133/internationalis ationagenda.pdf.

Tillman, Martin. 2012. "Employer Perspectives on International Education." In The SAGE handbook of intercultural higher education, edited by Darla K. Deardorff, Hans de Wit, John D. Heyl, and Tony Adams, 191-206. Los Angeles, CA: Sage.

Tirnaz, Samira, and Narafshan, Mehry H. 2018. "Promoting Intercultural Sensitivity and Classroom Climate in EFL Classrooms: The Use of Intercultural TV Advertisements." Learning, Culture and Social Interaction. https://doi.org/10.1016/j.Icsi.2018.10.001. 
Trilling, Bernie, and Charles Fadel. 2009. $21^{\text {st }}$ Century Skills. San Francisco, CA: John Wiley \& Sons Inc. Verschuren, Piet. J. M. 2002. “Dogma's en Ontwikkelingen in Wetenschap en Methodologie: Bedreigingen en Kansen" [Dogmas and Developments in Science and Methodology: Threats And Opportunities], 3-32. Accessed January 29, 2018.

https://www.researchgate.net/publication/40127719 Dogma's en ontwikkelingen in wetenschap en _methodologie_bedreigingen_en_kansen.

Young, Cheri A., Badiah Haffejee, and David L. Corsun. 2017. "The Relationship Between Ethnocentrism and Cultural Intelligence." International Journal of Intercultural Relations 58: 31-41.

https://doi.org/10.1016/j.jijintrel.2017.04.001. 


\section{APPENDIX A: Key Components from the Lesson Programmme's Workbook The four pillars of the sessions' design}

The lesson programme for the intercultural learning intervention consists of four sessions that each last two hours and fifteen minutes. To set the process in motion among students to break away from the culture of the truth a design was created that consists of four pillars.

Pillar 1: Practical cases as framework. All sessions revolve around practical intercultural (business) situations. A situation represents a challenge that students are likely going to experience during their studies/careers. The topics of each challenge are such that students can relate to them even if they have not yet literally experienced the situation. This is in line with the Creative Action Methodology (CAM) pedagogy parameter of using practical cases that fit students' experiences.

Pillar 2: Knowledge is not a fixed truth. In each session, students gain cultural knowledge from the literature to help students in making a breakdown of intercultural situations and to assess these from different perspectives. In line with the CAM parameters, the knowledge that is shared is not treated as a fixed truth. Instead, it is to be questioned through discourse and research.

Knowledge is gained in two ways during the sessions: Firstly, students share knowledge with each other. In line with the CAM parameters, knowledge components can consist of learners' prior knowledge, experiences, and their research findings from the literature. Secondly, knowledge components from the intercultural literature are shared by the moderator in a non-directive way. Knowledge that is shared also must be questioned by the person sharing it, for example, by pointing out to limitations to the research from which the knowledge was derived. Questioning knowledge is fundamental in CAM.

The questioning of cultural knowledge components also serves to help prevent the mere stereotyping of cultures. The concept of stereotyping touches on the culture of the truth because it does not involve critical thinking. Therefore, it is important that if students share ideas derived from cultural knowledge components, limitations to these ideas are also provided for.

Pillar 3: Culture might not form the only explanation. Although the focus of the sessions is developing students' intercultural sensitivity, it is important that students realise that culture might not be the only factor that plays a role in an intercultural (business) situation. Other factors, like personality or economics could also play a role. This realisation is important because otherwise the concept of culture by itself could become considered as a kind of 'truth.' Thus, in the sessions the idea of analysing a case from multiple perspectives also means that students consider other factors besides culture.

Pillar 4: Theory and evidence are not the same. In each session students create (innovative) solutions, by means of actions, to address a challenge. The actions must be informed by an explanation that serves to provide an understanding why an action would be effective to solve a case. To do this, students must provide explanations backed by empirical evidence. In the sessions students are taught that evidence is not the same as a theory and that a theory does not represent an all-encompassing truth. It is only a perspective based on logic. The understanding of the difference between a theory and evidence serves to help students realise that a theory might not necessarily represent the truth, but only a perspective to look at something. Pillar 4 also serves to help students question their perspectives to an intercultural situation and to question the effectiveness of their actions. In practice, this serves to help students become aware that while someone might see a particular solution as 'the best solution,' someone else might see that same solution as 'fruitless.' Table 3 provides an overview of the lesson programme and pillars. 
Table 3. Content of the Lesson Programme

\begin{tabular}{|c|c|c|c|c|c|c|}
\hline $\begin{array}{l}\text { Session } \\
\text { nr. }\end{array}$ & \multicolumn{2}{|l|}{ Focus: } & \multicolumn{2}{|l|}{ Themes: } & \multicolumn{2}{|c|}{$\begin{array}{l}\text { Cultural knowledge components from } \\
\text { the literature: }\end{array}$} \\
\hline 1 & \multirow{3}{*}{\multicolumn{2}{|c|}{$\begin{array}{l}\text { Students' future } \\
\text { internship abroad. }\end{array}$}} & \multicolumn{2}{|c|}{$\begin{array}{l}\text { Connecting to local people in } \\
\text { your 'dream' country. }\end{array}$} & \multicolumn{2}{|c|}{$\begin{array}{l}\text { 1. Values across cultures } \\
\text { regarding personal } \\
\text { relationships. }\end{array}$} \\
\hline \multirow[t]{2}{*}{2} & & & \multirow{2}{*}{\multicolumn{2}{|c|}{$\begin{array}{l}\text { Getting help from a local } \\
\text { colleague in your 'dream' } \\
\text { country. }\end{array}$}} & \multicolumn{2}{|c|}{$\begin{array}{l}\text { 1. Law and rules versus } \\
\text { relationships across cultures. }\end{array}$} \\
\hline & & & & & \multicolumn{2}{|c|}{$\begin{array}{l}\text { 2. Perception of time across } \\
\text { cultures. }\end{array}$} \\
\hline 3 & \multirow{2}{*}{\multicolumn{2}{|c|}{$\begin{array}{l}\text { Intercultural } \\
\text { conflict. }\end{array}$}} & $\begin{array}{l}\text { A Dutch busines } \\
\text { a local Indian ma }\end{array}$ & $\begin{array}{l}\text { erson upsets } \\
\text { ger. }\end{array}$ & \multicolumn{2}{|c|}{$\begin{array}{l}\text { 1. Values and behaviours across } \\
\text { cultures regarding leadership. }\end{array}$} \\
\hline 4 & & & $\begin{array}{l}\text { A Belgian emplo } \\
\text { local Dutch man }\end{array}$ & $\begin{array}{l}\text { e puzzles a } \\
\text { er. }\end{array}$ & \multicolumn{2}{|c|}{$\begin{array}{l}\text { 1. Degrees of comfort across } \\
\text { cultures regarding uncertain } \\
\text { situations. }\end{array}$} \\
\hline$\frac{\text { Pillar 1: }}{\text { Practical }}$ & \multicolumn{3}{|c|}{$\begin{array}{l}\text { Pillar 2: } \\
\text { Knowledge is not a fixed } \\
\text { truth }\end{array}$} & $\begin{array}{l}\text { Pillar 3: } \\
\text { Culture might } \\
\text { the only explar }\end{array}$ & $\begin{array}{l}\text { t form } \\
\text { tion }\end{array}$ & $\begin{array}{l}\text { Pillar 4: } \\
\text { Theory and evidence are } \\
\text { not the same }\end{array}$ \\
\hline
\end{tabular}

Note. This is an overview of the focus, themes, and cultural knowledge components for the sessions.

\section{The Seven Step Cycle and Content of the Sessions}

There is a seven-step cycle for each session to ensure that the four pillars in which the five actions were incorporated are applied in a structured way and within a certain time duration. A description of each step is provided below.

Preparation: The classroom for each session is set up in a meeting setting. The students and moderator jointly sit while facing each other: In line with the CAM pedagogy everyone's input matters. Students receive pens and papers to write down any ideas that pop up during the sessions. As an example, the first session is used to describe the seven steps.

Step 1. The challenge (+/- 10 minutes). At the beginning of each session, students are provided with a practical intercultural (business) case that students will likely experience during their studies/careers. The moderator shares this case verbally. To illustrate, in session one students are asked to write down actions to successfully connect to the local people in a country they are eager to work in.

Step 2. The exchange (+/- 5 minutes). In the second step of the cycle, all students are asked to share their initial ideas. In session one students are invited to share their actions with the group. The moderator writes down students' ideas to get an overview. Following the CAM parameters, no judgements are made to these ideas so that students can freely share their input.

Step 3. Discourse (+/- 35 minutes). In session one, students must formulate an explanation why they think their actions could be effective. Explanations must be informed by evidence. Therefore, in session one students are also taught the difference between theory and evidence.

The focus of the discussion is questioning how convincing the explanations are, whether they give a more profound understanding to the case, and how convincing the evidence is. To fuel discourse, questions such as "how do you know that this is true?" or "do you think that the explanation you gave applies to all people in that country?" are posed. This serves to trigger students' 
thinking and to 'destabilise' their orientation towards the culture of the truth. Through discourse students learn there could be multiple perspectives to look at a situation. The questions in step three also function to have students further develop their cultural self-awareness and deep cultural knowledge of other cultures through what they learn from the literature and discussions.

To further develop students' ability to view a case from multiple perspectives and to become aware that there are multiple solutions possible, questions in step three are varied per session. For example, questions include asking students to think of disadvantages to actions shared by another student even if they agree with another student's actions. Thus, students learn to think in opposite directions of any perspective. The use of variation in the questions in step three also functions to offer students a continuously changing learning environment which is an important element in the CAM pedagogy.

After in-class discourse in step three students are given time to reconsider their explanations and evidence. All students are then asked to share their (adapted) explanations with evidence. The moderator writes down these explanations. These are readdressed in step four and five. Furthermore, the moderator provides (an) additional cultural knowledge component(s) from the intercultural literature, concerning values and behaviours.

Step 4. Taking stock (+/- 5 minutes). In step four the teacher writes down all explanations discussed in step three on the white board. Students in the meantime are offered a short break.

Step 5. Inquiry and selection (+/- 30 minutes). In step five, students are presented with a list of the explanations brought forward in step three. Students are then given time to go over this list and to conduct research, using among others intercultural literature. With this students can determine which explanation from the list is their preferred explanation to provide an understanding to the case. The conduct of research in step five also functions to further develop students' cultural self-awareness and deep cultural knowledge of other cultures. Students conduct research using any resource they wish to use. For example, students can browse the Internet or call someone who might have experience with the case's theme. Students can even conduct research together if they have preference for the same explanation. A key rule of step five is that students stay inside the classroom.

Students are encouraged by the teacher to pick a preferred explanation that fits their research findings even if this goes against their own initial explanation. In part this is in line with the CAM parameter of giving contradictory advice. This serves to develop a more investigative, open and respectful attitude to other perspectives. Students have to argue for a preferred explanation by also arguing why other explanations are less/not preferred. This argumentation has to be based on evidence as well.

Step 6. The solution phase (+/- 20 minutes). Once students have made a choice for a preferred explanation, students design several new actions to successfully solve the case based on their preferred explanation. During this step students can get advice from the moderator. In session one students have to create several new actions to connect successfully to local people. This step serves to have students create actions based on an explanation that provides an understanding, backed by evidence, why their actions could work in a certain cultural context. Students have to think of multiple actions rather than only one. This serves to trigger their critical and analytical skills and their creativity.

Step 7. Show time (+/- 30 minutes). In the final step students pitch their actions to solve a case: Students share their preferred explanation to provide an understanding to the case with arguments backed by evidence and their solution to solve the case. In session 1 the students listening to the pitch show either green or red cards to indicate whether they find the pitch convincing or not. 
The moderator asks students to provide feedback and space is given to discuss with the student who pitched.

To create variation in step seven this step is altered in other sessions. For instance, students listening to a pitch must take the position of not feeling convinced by the ideas from the pitch even if they actually are convinced. Variation in step seven serves to create a changing learning environment during the sessions. This is also in accordance with CAM. Step seven also serves to trigger students to use their critical and analytical thinking and their creativity by thinking of opposing viewpoints. This step also serves to develop a more open, investigate and respectful attitude among students towards perspectives that differ from their own.

Copyright for the content of articles published in Teaching \& Learning Inquiry resides with the authors, and copyright for the publication layout resides with the journal. These copyright holders have agreed that this article should be available on open access under a Creative Commons Attribution License 4.0 International (https://creativecommons.org/licenses/by-nc/4.0/). The only constraint on reproduction and distribution, and the only role for copyright in this domain, should be to give authors control over the integrity of their work and the right to be properly acknowledged and cited, and to cite Teaching \& Learning Inquiry as the original place of publication. Readers are free to share these materials-as long as appropriate credit is given, a link to the license is provided, and any changes are indicated. 